\title{
RESISTANCE OF A RED LATOSOL TO PENETRATION: COMPARISON OF PENETROMETERS, MODEL ADJUSTMENT, AND SOIL WATER CONTENT CORRECTION
}

\author{
Thiago F. Duarte ${ }^{1 *}$, Tonny J. A. da Silva ${ }^{1}$, Edna M. Bonfim-Silva ${ }^{1}$, Willian Fenner ${ }^{1}$ \\ ${ }^{1 *}$ Corresponding author. Universidade Federal de Rondonópolis/ Rondonópolis - MT, Brasil. \\ E-mail: thiago.duarte@ufr.edu.br | ORCID ID: https://orcid.org/0000-0002-8471-104X
}

\section{KEYWORDS}

soil physics, soil mechanical, soil compaction, modeling.

\begin{abstract}
Penetration resistance can be determined directly in the field or in the laboratory. However, data obtained using the two methods are not directly comparable. Considering soil moisture influences penetration resistance, penetration resistance data obtained using the two methods can be corrected based on common moisture values. To enable comparison of the data, the measured data should be adjusted using mathematical models. Consequently, the objective of the present study was to compare soil penetration resistance values measured in a Red Latosol using a static penetrometer and a bench-top electronic penetrometer. The comparison was carried out using samples collected from different soil layers, based on moisture levels ranging from 0.15 to $0.28 \mathrm{~kg} \mathrm{~kg}^{-1}$. In addition, the reliability of some mathematical models was compared using benchpenetrometer data. Finally, the Busscher method and a new proposed method for moisture correction were tested. According to the comparison of results between the equipment, it is necessary to correct data using a linear type equation. The Jakobsen \& Dexter (1987) model had the optimal performance ( $\mathrm{R}^{2}: 0.89$; RMSD: 0.70$)$. The new proposed corrected method was tested using several reference moisture values and it presented minor $(<0.30$ RMSD) and stable errors.
\end{abstract}

\section{INTRODUCTION}

In Brazil, the Cerrado region contributes significantly to the agricultural production in the country. In the region, large-scale commercial cultivation of crops such as soybeans, corn, and cotton, is fully mechanized, with intense machine and equipment traffic associated with management activities. Consequently, soil may be compacted, particularly if managed under poor soil moisture conditions.

The degree of soil compaction can be evaluated using some physical soil indices such as soil bulk density and total porosity. Another alternative is the evaluation of the resistance of the soil against mechanical penetration, which consists of quantifying the resistance observed against the penetration of a body of a certain shape, usually a cone (Medvedev, 2009). Such evaluations offer essential information with regard to the ease or difficulty of the growth of root systems of crops.

The equipment currently available in the market allow penetration resistance to be evaluated directly in the field, for example, using manual penetrometers, or in the laboratory, for example, using bench-top penetrators. The results of field penetrometers depend on user operating speed, which is often challenging to standardize. A change in operating speed alters the force the users applies to insert the equipment rod, which, in turn, changes the result (Filho et al. 2014). Bench penetrometers, conversely, are automatic, and the measurements are not influenced by the user. However, the area of the base of a ground-penetrating cone in a bench-top penetrometer is significantly lower when compared to the area of the base of a cone in a field penetrometer, which may be another source of variation in the results of the two instruments (Junior et al. 2014).

Penetration resistance is influenced entirely by soil moisture, as already demonstrated by several authors (Vaz et al. 2011; Silva et al. 2016), and there is a general trend of reduction (exponential) in penetration resistance with an increase in soil moisture, which is attributed to the lubricating effect of moisture on cone penetration. Consequently, to compare values measured under different moisture conditions and ensure reliable comparisons, the data obtained should be

\footnotetext{
${ }^{1}$ Universidade Federal de Rondonópolis/ Rondonópolis - MT, Brasil.
} 
first corrected as a function of soil moisture. In data correction activities, Mathematical models adjusted based on experimentally obtained data are often required in data correction activities. Existing models are diverse, such as those of Busscher \& Sojka (1987), Jakobsen \& Dexter (1987), Mielke et al. (1994), and Busscher et al. (1997), and often have one or two independent variables, mostly soil bulk density and moisture. Selecting a model that best fits the data is always recommended to minimize errors arising from moisture correction.

The objectives of the present study were to (1) compare the mechanical resistance to penetration in a Red Latosol, based on measurements obtained using two penetrometers, a static penetrometer (PLG1020, PenetroLOG ${ }^{\circledR}$, Falker, Porto Alegre, Brazil) and a bench-top electronic penetrometer (MA 933, Marconi, Sao Paulo, Brazil), under various soil moisture conditions; compare mathematical models adjusted to experimental data, and (2) correct penetration resistance values as a function of soil moisture using the method of Busscher et al. (1997) and a new proposed method.

\section{MATERIAL AND METHODS}

\section{Experiment general data}

The experiments were carried out from May to October 2018 at the Federal University of Mato Grosso, Rondonópolis University Campus ( $16^{\circ} 28^{\prime} \mathrm{S} ; 50^{\circ} 34^{\prime} \mathrm{O} ; 284 \mathrm{~m}$ a.s.l). The local climate is Aw (tropical humid), according to the Köppen classification, and the soil is classified as a Red Latosol (Embrapa, 2018) (Clay: 41\%; Sand: 40\%; and Silt: 19\%). Penetration resistance measurements were carried out in two steps, as described below.

\section{Experiment 1: Measured field penetration resistance data and penetrometer comparison}

An area without vegetation was selected and delimited using a galvanized steel sheet structure $4.0 \mathrm{~m}$ in diameter, 0.20 $\mathrm{m}$ deep, and protruding $0.10 \mathrm{~m}$ above the soil surface, to facilitate saturation. An access tube was installed at the center of the plot for moisture measurements using a Diviner $2000^{\circledR}$ probe (Sentek com, Australia). Prior to the start of measurements, the experimental plot was saturated with water (Figure 1).

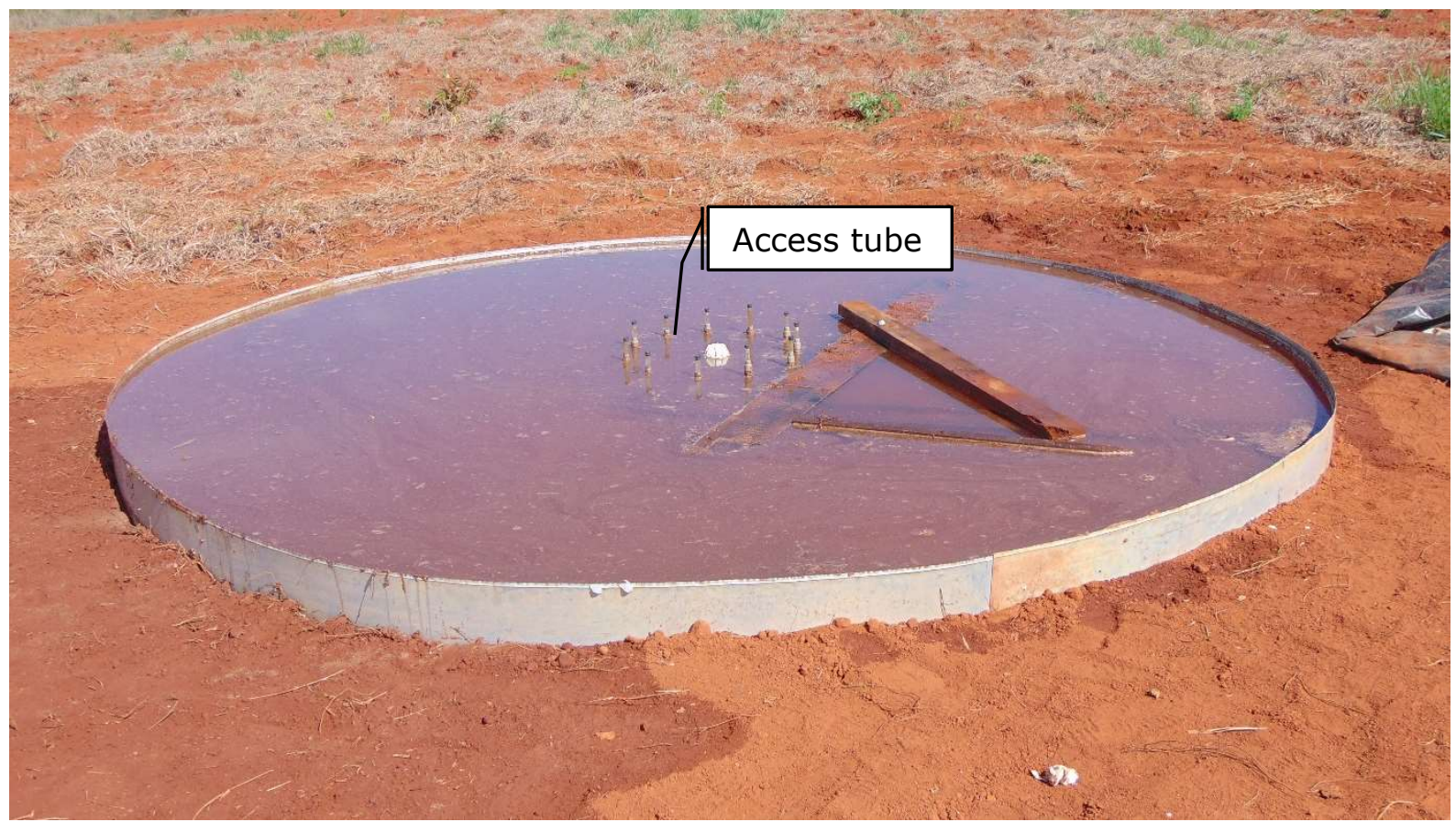

FIGURE 1. Red Latosol saturation process in the study plot. Detail demonstrating access tube for moisture measurement with Diviner 2000 probe.

To evaluate the variation of penetration resistance as a function of soil moisture under field conditions, measurements were performed during soil drying with a manually operated penetrometer (PLG 1020 PenetroLOG ${ }^{\circledR}$ ) with a cone base area of $1.29 \times 10^{-4} \mathrm{~m}^{2}$. Measurements were obtained up to a depth of $0.6 \mathrm{~m}$ at $0.1-\mathrm{m}$ intervals. Measurements were made over six days, between 22/05/18 to 04/06/18. Penetration resistance was measured every day, and soil moisture was also measured using the Diviner $2000^{\circledR}$ probe to a depth of $0.6 \mathrm{~m}$, at $0.1-\mathrm{m}$ intervals. Consequently, pairs of penetration resistance and soil moisture values were obtained for each layer.

To compare the performance of the PLG1020 penetrometer and the bench-top penetrometer (MA 933/Marconi), penetration resistance measurements were performed using the two equipment in three random days with varying soil moisture conditions. Therefore, after determining the resistance with a manual penetrometer, undisturbed samples (steel cylinders with heights and diameters of 5.5 and $4.9 \mathrm{~cm}$, respectively) were collected for resistance measurements with the bench-top penetrometer. Sample collections were performed as close as possible to the resistance measurements times using the field equipment. At each evaluation, samples were collected at $0-0.05,0.10-0.15$, $0.15-0.20,0.20-0.25$, and $0.30-0.35 \mathrm{~m}$ layers, with three replicates. In the laboratory, the MA 933 penetrometer was set at a rod travel speed of $10 \mathrm{~mm} \mathrm{~min}^{-1}$, and the cone base area was $7.1 \times 10^{-6} \mathrm{~m}^{2}$. The penetration resistance values used were the averages of the repetitions of each layer.

The differences between the equipment was analyzed using the Student's t-test by comparing means of paired samples at 5\% probability level. 


\section{Experiment 2: Laboratory-measured penetration resistance for model adjustment}

Twenty undisturbed samples were collected using a steel cylinder (height: $5.5 \mathrm{~cm}$; diameter: $4.9 \mathrm{~cm}$ ) in the 0 to $0.20-\mathrm{m}$ layer. Subsequently, the samples were saturated, separated into 5 groups (4 samples per group), and subjected to different pressures in a Richards chamber to eliminate sample moisture and promote moisture variation. The pressure values adopted were $0.33,1.0,5.0,10$, and 15 Bar.

In another step, to increase the number of data points for use in the adjustment of the models, 20 more undisturbed samples were collected. The samples were saturated and ovendried to promote the induction of moisture bands. The samples were dried for $2 \mathrm{~h}, 3 \mathrm{~h}$, and $15 \mathrm{~h}$, at $105^{\circ} \mathrm{C}$, and finally, for 24 $\mathrm{h}$ at $105^{\circ} \mathrm{C}$, to obtain dry weight and moisture values. After each drying step, penetration resistance was measured using the MA933 penetrometer, with a displacement velocity of 10 $\mathrm{mm} \mathrm{min}^{-1}$ and a cone area $7.1 \times 10^{-6} \mathrm{~m}^{2}$. The tests performed in the two steps yielded 80 penetration resistance analyses.

\section{Models evaluation}

To evaluate the models, only the samples analyzed using the MA933 bench-top penetrometer were used. The values obtained were input into four mathematical models described below:

Model of Busscher \& Sojka (1987):

$$
P R=a \rho_{d}^{b} \theta_{m}^{c}
$$

Where:

$$
\begin{aligned}
& \mathrm{PR}=\text { penetration resistance }(\mathrm{MPa}) \\
& \rho_{\mathrm{d}}=\text { bulk density }\left(\mathrm{kg} \mathrm{m}^{-3}\right) \\
& \theta_{\mathrm{m}}=\text { soil water content on a mass basis }\left(\mathrm{kg} \mathrm{kg}^{-1}\right), \\
& a, b \text { and } c \text { are model fit coefficients. }
\end{aligned}
$$

Model of Busscher et al. (1997):

$$
P R=a \exp \left(b \theta_{m}\right)
$$

Where:

$$
\begin{aligned}
& \mathrm{PR}=\text { penetration resistance }(\mathrm{MPa}) \\
& \theta_{\mathrm{m}}=\text { soil water content on a mass basis }\left(\mathrm{kg} \mathrm{kg}^{-1}\right), \\
& a \text { and } b \text { are model fit coefficients. }
\end{aligned}
$$

Model of Jakobsen \& Dexter (1987):

$$
P R=\exp \left(a+b \rho_{d}+c \theta_{m}\right)
$$

Where:

$$
\begin{aligned}
& \mathrm{PR}=\text { penetration resistance }(\mathrm{MPa}) ; \\
& \rho_{\mathrm{d}}=\text { bulk density }\left(\mathrm{kg} \mathrm{m}^{-3}\right) ; \\
& \theta_{\mathrm{m}}=\text { soil water content in mass basis }\left(\mathrm{kg} \mathrm{kg}^{-1}\right), \\
& a, b \text { and } c \text { are model fit coefficients. }
\end{aligned}
$$

And, model of Mielke et al. (1994):

$$
P R=a \theta_{m}^{b}
$$

Where:

$$
\begin{aligned}
& \mathrm{PR}=\text { penetration resistance }(\mathrm{MPa}) \\
& \theta_{\mathrm{m}}=\text { soil water content on a mass basis }\left(\mathrm{kg} \mathrm{kg}^{-1}\right), \\
& a \text { and } b \text { are model fit coefficients. }
\end{aligned}
$$

The models were adjusted using the solver function in MS Excel (Microsoft Corp., Redmond, WA, USA), by minimizing the squared sum of the deviations. The quality of fit was assessed with the coefficient of determination $\left(\mathrm{R}^{2}\right)$ and root-mean-square deviation.

\section{Correction of penetration resistance by soil moisture}

To correct the penetration resistance as a function of soil moisture, the model proposed by Busscher et al. (1997) was evaluated, using the following equation:

$$
P R c=P R_{0}+d C / d \theta\left(\theta_{\text {ref }}-\theta_{0}\right)
$$

Where:

PRc: corrected penetration resistance (MPa);

$\mathrm{PR}_{0}$ : measured penetration resistance $(\mathrm{MPa})$;

$\mathrm{dC} / \mathrm{d} \theta$ : according to Busscher, is the first derivative of any model of the type PR $\left(\theta_{\mathrm{m}}\right)\left(\mathrm{MPa} \mathrm{kg}^{-1}\right)$, which was calculated as $\mathrm{dC} / \mathrm{d} \theta=\mathrm{ab} \theta_{\mathrm{m}}{ }^{(\mathrm{b}-1)}$;

$\theta_{\text {ref: }}$ is the common water content for which the penetration resistance was corrected $\left(\mathrm{kg} \mathrm{kg}^{-1}\right)$,

$\theta_{0}$ : soil moisture $\left(\mathrm{kg} \mathrm{kg}^{-1}\right)$.

In addition, a simple and alternative method of correction was proposed. The method consists of the following steps:

1 - Calculate the difference $\Delta(\theta)$ between the measured penetration resistance value and the reference penetration resistance value:

$$
\Delta(\theta)=P R_{\text {measured }}-P R_{\text {ref }}
$$

Where:

$$
\begin{aligned}
& \mathrm{PR}_{\text {measured }} \text { : penetration resistance measured under any } \\
& \text { soil moisture conditions }(\mathrm{MPa}) \text {, } \\
& \mathrm{PR}_{\text {ref: penetration resistance at common water content }} \\
& (\mathrm{MPa}) \text {. }
\end{aligned}
$$

2 - Subsequently, a polynomial model is adjusted based on the values $\Delta(\theta)$ obtained, according to Figure 2 . 


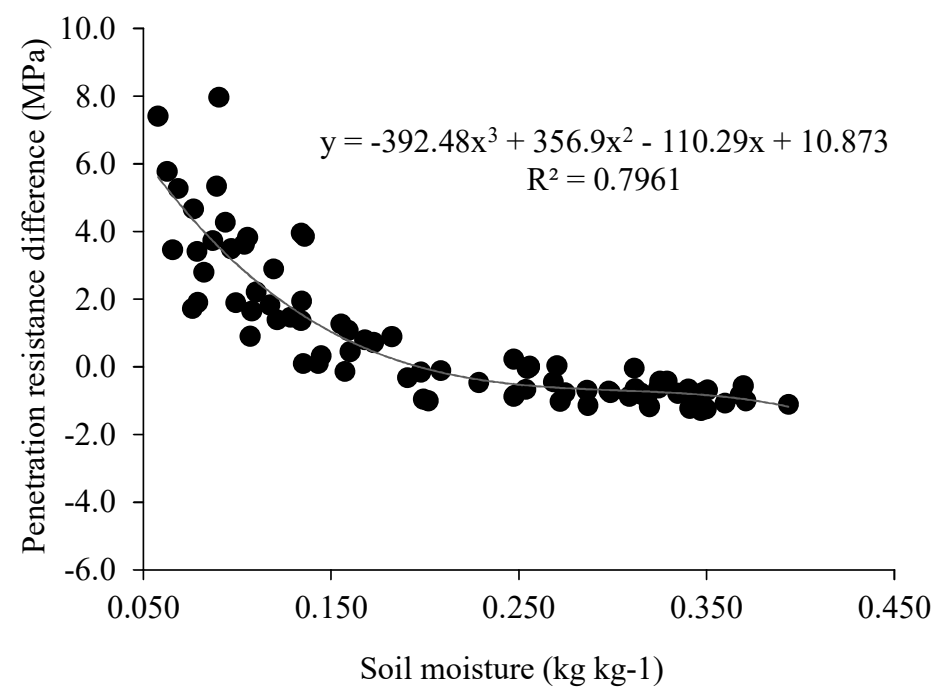

FIGURE 2. Difference between measured penetration resistance and the reference penetration resistance $\left(\right.$ at $\left.\theta_{\mathrm{m}}=0.20 \mathrm{~kg} \mathrm{~kg}^{-1}\right)$ as a function of soil moisture.

3 - Finally, penetration resistance value measured under any soil moisture contents are measured under the following conditions:

if:

$$
\begin{aligned}
& \theta_{\mathrm{i}}>\theta_{\text {reference }}: \\
& \quad \mathrm{PR}_{\text {cor }}=\mathrm{PR}_{i}+\mid \text { cor } \mid \\
& \text { or: } \\
& \theta_{\mathrm{i}}<\theta_{\text {reference }}: \\
& \quad \mathrm{PR}_{\text {cor }}=\mathrm{PR}_{i}-\mid \text { cor } \mid
\end{aligned}
$$

Where:

$$
\theta \mathrm{i} \text { : any soil moisture content }\left(\mathrm{kg} \mathrm{kg}^{-1}\right) \text {; }
$$

Oref: similar to in the case of Busscher, it is the common water content based on which the penetration resistance was corrected $\left(\mathrm{kg} \mathrm{kg}^{-1}\right)$;

$\mathrm{PR}_{\text {cor }}$ : corrected penetration resistance $(\mathrm{MPa})$;

$\mathrm{PR}_{\mathrm{i}}$ : current penetration resistance measured in $\theta \mathrm{i}$ $(\mathrm{MPa})$,

|cor|: an absolute value of the correction to be applied to the data $(\mathrm{MPa})$, obtained using the polynomial function presented in Figure 2.

The data used to evaluate the moisture correction methods were obtained from an independent data set. For this, 20 undisturbed soil samples were collected. The samples were separated into six groups, and each group was subjected to pressure in a Richards chamber. The pressures conditions were $10,100,300$, and $500 \mathrm{kPa}$. After stabilization, the samples were weighed and subjected to penetration resistance test using the bench penetrometer, as previously described. The average soil bulk density of the samples was $1.27 \mathrm{~g} \mathrm{~cm}^{-3}$, and soil moisture ranged from 0.15 (at $500 \mathrm{kPa}$ ) to $0.25 \mathrm{~kg} \mathrm{~kg}^{-1}$ (at $10 \mathrm{kPa}$ ).

The reference penetration resistance value $\left(\mathrm{PR}_{\mathrm{ref}}\right)$ used under both correction methods (Busscher method and the proposed method) was obtained using equation 9. The equation was obtained by fitting the simple power model to the data measured using the MA 933 penetrometer. The models were evaluated for $\theta_{\text {reference }}$ under moisture levels ranging from 0.10 to $0.30 \mathrm{~kg} \mathrm{~kg}^{-1}$, with $0.10-\mathrm{kg} \mathrm{kg}^{-1}$ intervals. Therefore, the $\mathrm{PR}_{\text {ref }}$ values evaluated were $4.39,2.66,1.87,1.42$, and 1.13 $\mathrm{MPa}$, respectively, for the $\theta_{\text {reference }}$ values.

$$
P R=0,2562 \theta_{m}^{-1,234}
$$

\section{RESULTS AND DISCUSSION}

\section{Field penetration resistance and penetrometer comparison}

The variation in penetration resistance as a function of soil moisture was conditioned to measurement depth. In the 0 $0.1 \mathrm{~m}, 0.1-0.2 \mathrm{~m}, 0.2-0.3 \mathrm{~m}$, and $0.30-0.40 \mathrm{~m}$ soil layers, there was a high correlation between penetration resistance and soil moisture, with $\mathrm{R}^{2}$ values of $0.986,0.985,0.665$, and 0.6895 , respectively (Figure 3A, B, C, and D). However, at other depths, there were relatively low levels of correlation between the two, indicated by low coefficient of determination values (Figure $3 \mathrm{E}$ and $\mathrm{F}$ ). The results were due to the minor variation in soil moisture in the deepest layers. In the 0.5-0.6-m layer, soil moisture varied by $3 \%$, compared to $15 \%$ in the $0-0.1-\mathrm{m}$ layer. From a depth of $0.6 \mathrm{~m}$, the difference between the values measured at the beginning and the end of the experiment was practically non-existent, based on the penetration resistance profile (Figure 4). 

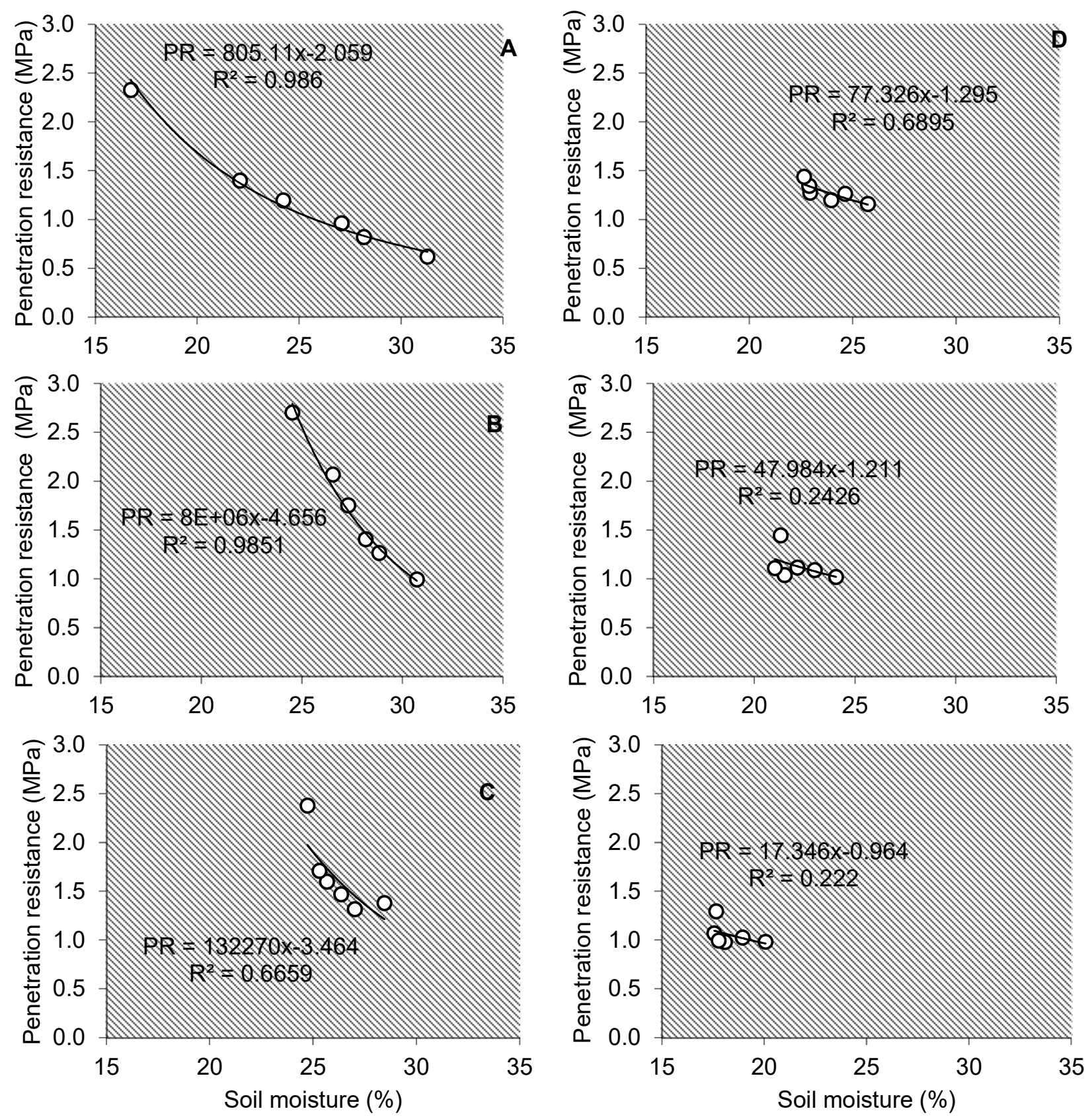

FIGURE 3. Penetration resistance measured under field conditions using a manual penetrometer, as a function of volumetric soil moisture (\%). A) 0-0.10 m layer; B) 0.10-0.20 m layer; C) $0.20-0.30 \mathrm{~m}$ layer; D) $0.30-0.40 \mathrm{~m}$ layer; E) $0.40-0.50 \mathrm{~m}$ layer; F) $0.50-0.60 \mathrm{~m}$ layer.

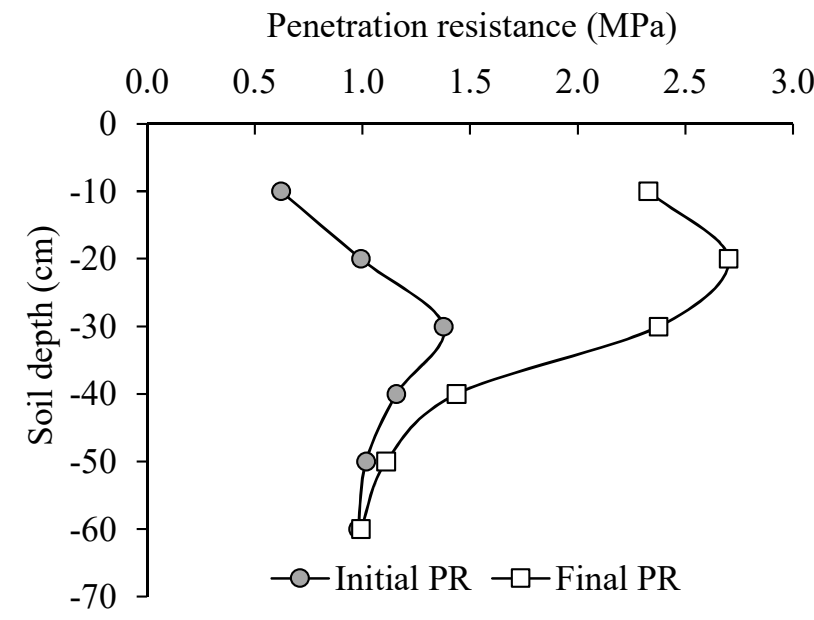

FIGURE 4. Penetration resistance profile measured using a manual penetrometer under field conditions at the beginning (PR initial) and at the end (PR final) of the experiment. 
Comparison of penetration resistance results obtained under two sampling conditions, i.e., in the field, using the PLG1020 static penetrometer, and in the laboratory, using the MA933 bench-top electronic penetrometer, revealed different results, which were compared under different soil moisture values (Figure 5). Measurements obtained using the laboratory penetrometer yielded higher penetration resistance values than measurements obtained under field conditions for similar soil moisture values. The penetration resistance evaluations were conducted using soil moisture conditions ranging from 0.15 to $0.27 \mathrm{~kg} \mathrm{~kg}^{-1}$, representing field capacity and the permanent wilt point, respectively, in the studied soil. There were significant differences between the values obtained using the two equipment based on Student's t-test $(\mathrm{p}<0.05)$, according to Table 1. Using both types of penetrometers, the penetration resistance values exhibited similar trends based on soil moisture. However, there was a wide difference in the measured values. However, the bench-top penetrometer yielded higher penetration resistance values when compared to the values obtained using the field penetrometer. The values obtained using the bench-top penetrometer were on average almost 3.0-fold those obtained using the field penetrometer, according to the angular coefficient adjusted to the data. Nevertheless, the correlation coefficient between the values obtained using the two equipment was $\mathrm{R}^{2}=0.72$ (Figure 6).

TABLE 1. Student t-test results for penetration resistance values measured using a field (PR -field) and bench-penetrometer (PR - bench).

\begin{tabular}{ccc}
\hline & $P R-$ bench $(\mathrm{MPa})$ & $P R-$ field $(\mathrm{MPa})$ \\
\hline Mean & 4.18 & 1.45 \\
Variance & 4.46 & 0.56 \\
Observations & 44 & 44 \\
Pearson correlation & 0.85 & 0.00 \\
Difference means hypothesis & 43 \\
gl. & 11.81 \\
$\mathrm{Stat} \mathrm{t}$ & 0.00 \\
$\mathrm{t}$ critical uni-caudal & 1.68 \\
$\mathrm{P}(\mathrm{T}<=\mathrm{t})$ bi-caudal & 0.00 \\
$\mathrm{t}$ critical bi-caudal & 2.02 \\
\hline
\end{tabular}

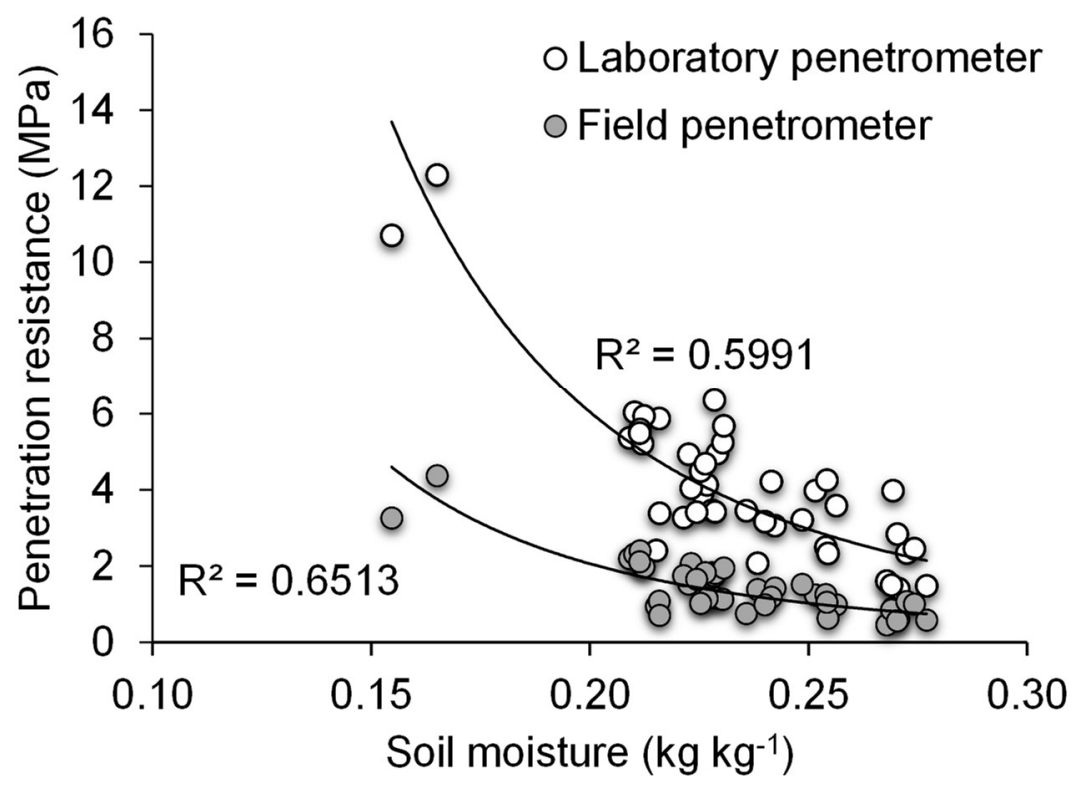

FIGURE 5. Penetration resistance curves measured in the field (manual penetrometer) and in the laboratory (bench-top penetrometer) as a function of soil water content mass basis $\left(\theta_{\mathrm{m}}=\mathrm{kg} \mathrm{kg}^{-1}\right)$. 


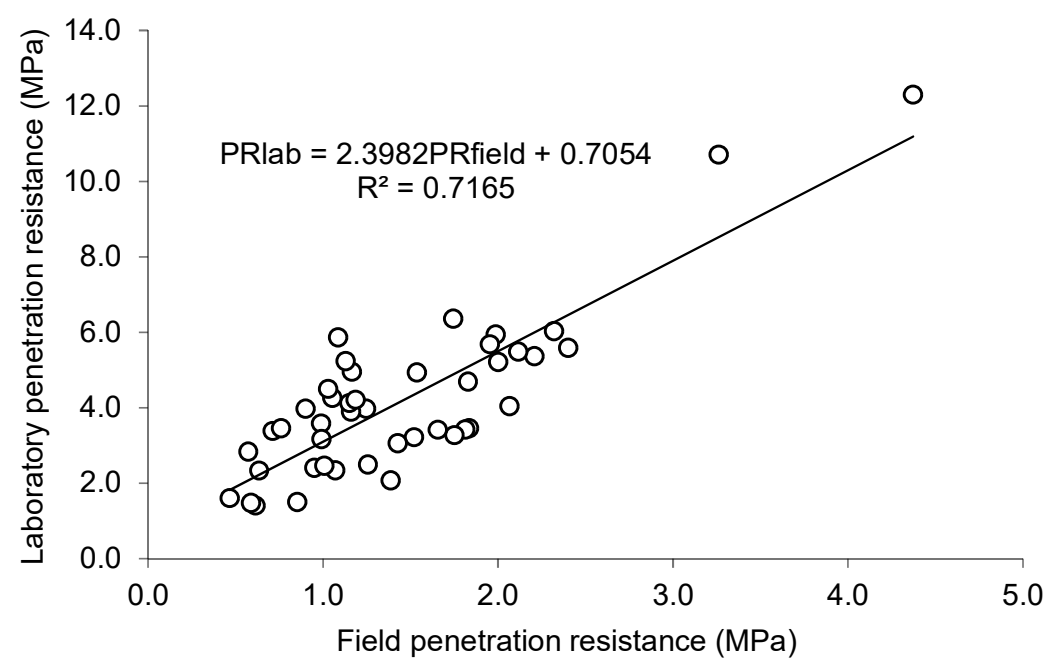

FIGURE 6. Regression between penetration resistance measured in the field (manual penetrometer) and laboratory (bench-top penetrometer) as a function of soil water content.

According to the results, the penetration resistance values obtained using the two sets of equipment are not comparable. The bench-top penetrometer has a base area of 7.1 $\mathrm{x} 10^{-6} \mathrm{~m}^{2}$ while the field penetrometer has a base area of 1.29 $\mathrm{x} 10^{-4} \mathrm{~m}^{2}$, which translates to an approximate 18 -fold difference. Therefore, to enable data comparison, it is necessary to adjust the values using the following equation first:

$$
\mathrm{PR}_{\text {lab }}=2.3982 \mathrm{PR}_{\text {field }}+0.7054 \text { (Figure 6). }
$$

The penetration resistance that would be obtained using the bench-top penetrometer is estimated using the equation above, based on the penetration resistance measured using the field penetrometer. Conversely, the following equation: $\mathrm{PR}_{\text {field }}$ $=0.2988 \mathrm{PR}_{\mathrm{lab}}+0.1988$, is used to estimate the penetration resistance that would be obtained using the field penetrometer based on the values obtained using a bench-top penetrometer.

Some authors have observed differences in the penetration resistance values estimated using penetrometers with varying cone areas (Hernanz et al. 2000; Junior et al. 2014). However, both studies were undertaken under laboratory conditions. Junior et al. (2014) used an automated bench-top electronic penetrometer in a Red-Yellow Latosol with clayey-sandy texture, and they compared the results obtained using penetrometers with cone base areas of 10.98 and $129.28 \mathrm{~mm}^{2}$. According to the results, the penetration resistance values obtained using penetrometers with smaller base areas were relatively higher, regardless of moisture and bulk density conditions. Hernanz et al. (2000) evaluated the results of penetrometers with cone base areas ranging from $26 \mathrm{~mm}$ to $175 \mathrm{~mm}^{2}$ in a Vertic Luvisol with loamy texture. They reported an increase in data variability, based on the coefficient of variation values, in addition to higher penetration resistance values obtained with a decrease in cone basal area. However, the cone basal area did not influence the penetration resistance value when the size of the cone base was greater than $100 \mathrm{~mm}^{2}$.

The differences in penetration resistance values observed among cones can be explained according to Junior et al. (2014), who posit that there must be cracks in along the path of penetration for cones to penetrate the soil. Larger cones generate relatively larger cracks as they pass along the soil layers $=$, which enables penetration into the ground with less resistance over longer periods, when compared to the cases in cones with smaller base areas. Consequently, cones of different sizes would generate different rupture planes, and, in turn, the force opposing the movement of the cones would vary, resulting in lower penetration resistance values for penetrometers with larger cones.

\section{Penetration resistance with bench-top penetrometer and model fitting}

Figure 7 represents the penetration resistance data obtained using the bench-top penetrometer. The values were measured in soils with a wide range of moisture conditions, ranging from 0.06 to $0.39 \mathrm{~kg} \mathrm{~kg}^{-1}$, and the penetration resistances values ranged from 9.84 to $0.58 \mathrm{MPa}$, respectively. The average soil bulk density was $1.27 \mathrm{~g} \mathrm{~cm}^{-3}$, and the minimum and maximum values were 1.07 and $1.41 \mathrm{~g} \mathrm{~cm}^{-3}$, respectively, and there was no correlation between penetration resistance and soil bulk density. 


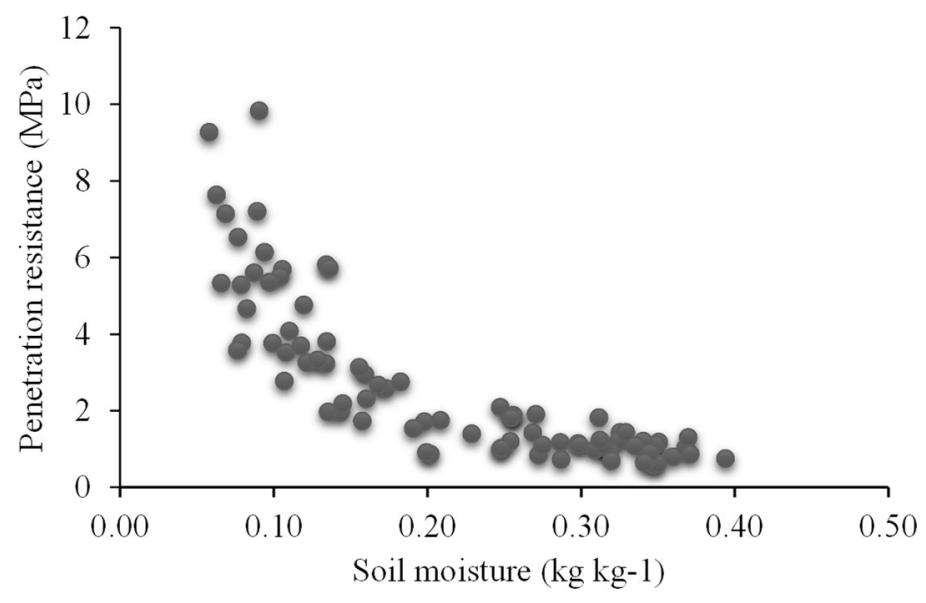

FIGURE 7. Penetration resistance as a function of soil water content mass $\left(\theta_{\mathrm{m}}=\mathrm{kg} \mathrm{kg}^{-1}\right)$ measured using a bench-top penetrometer.

Table 2 lists the adjusted parameters for the evaluated models. Penetration resistance simulations with the fitted models and their correlation with the measured data are illustrated in Figures 8 to 11. In general, the models that did not consider soil bulk density (equation 2 and equation 4) had the largest simulation errors. The highest correlation was obtained using the model of Jakobsen \& Dexter (1987), followed by the models of Busscher \& Sojka (1987), Mielke et al. (1994), and Busscher et al. (1997). Similar trends were observed in the root mean square deviation (RMSD), whose maximum and minimum values were 1.01 and 0.70 , based on the Busscher et al. (1997) and Jakobsen and Dexter (1987) models, respectively. However, in all models, there was a greater tendency for dispersion to lower soil moisture levels, ie, in the range of higher values of penetration resistance, as illustrated in Figures 8 to 11 . The trends were more pronounced in the models of Mielke et al. (1994) and Busscher et al. (1997).

In other soil classes (Quartzarenic Neosol and Latosols), Vaz et al. (2011), also observed that the Jakobsen \& Dexter (1987) model presented the best fit for the data when compared with several other models. In addition, in the results presented by the authors, the equations were influenced only by soil moisture, had errors higher than 2.0 (RMSD), and a $\mathrm{R}^{2}$ close to 0.65 , demonstrating the poor reliability of the models.

TABLE 2. Adjusted parameters of the evaluated penetration resistance models.

\begin{tabular}{cccc}
\hline Penetration resistance models & \multicolumn{3}{c}{ Adjusted parameters } \\
\cline { 2 - 5 } & $\mathrm{a}$ & $\mathrm{b}$ & -1.3000 \\
Busscher \& Sojka (1987) & 0.0712 & 5.0589 & - \\
Busscher et al. (1997) & 11.5189 & -8.49036 & -10.1530 \\
Jakobsen \& Dexter (1987) & -2.6716 & 4.2082 & - \\
Mielke et al. (1994) & 0.3223 & -1.1479 & - \\
\hline
\end{tabular}

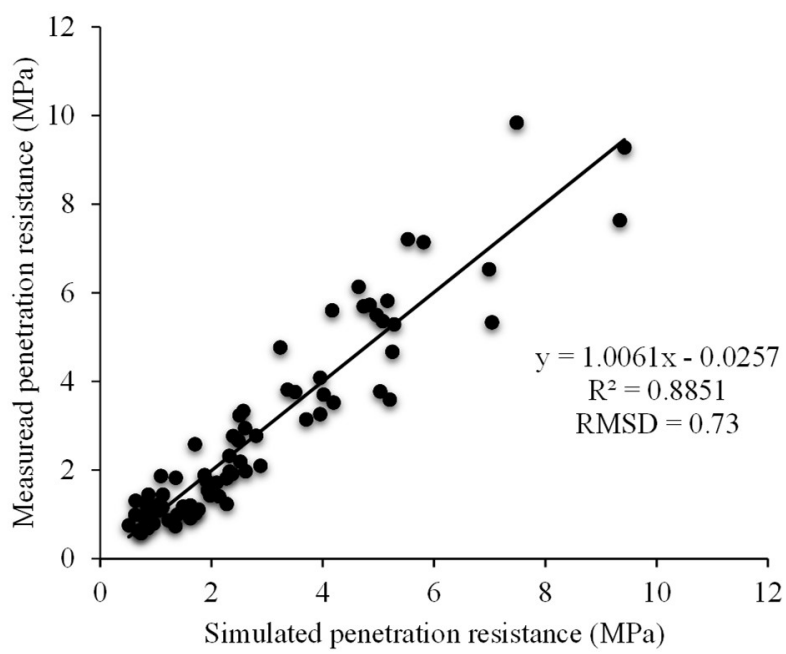

FIGURE 8. Comparison of measured and simulated penetration resistance (PR) values using the Busscher \& Sojka (1987) model. 


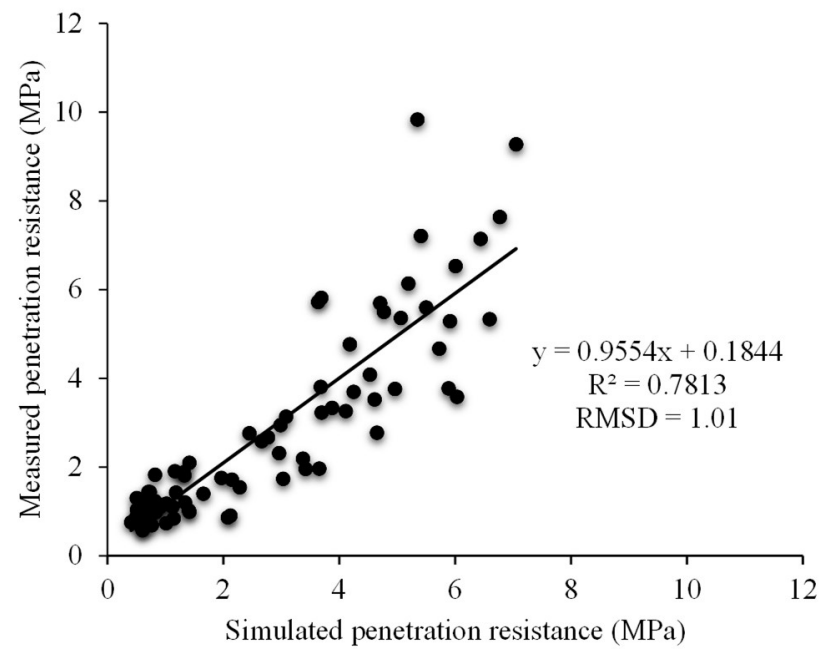

FIGURE 9. Comparison of measured and simulated penetration resistance (PR) values using the Busscher et al. (1997) model.

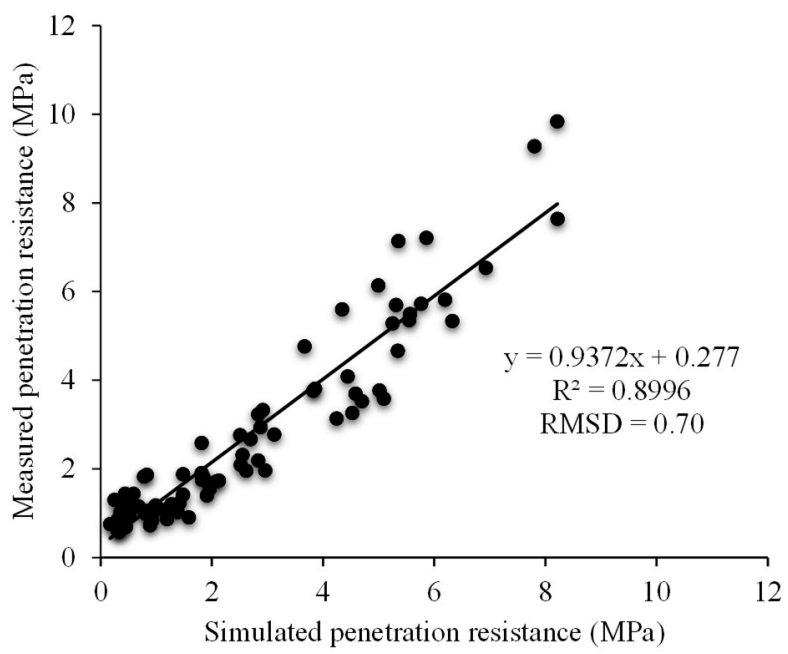

FIGURE 10. Comparison of measured and simulated penetration resistance (PR) values using the Jakobsen \& Dexter (1987) model.

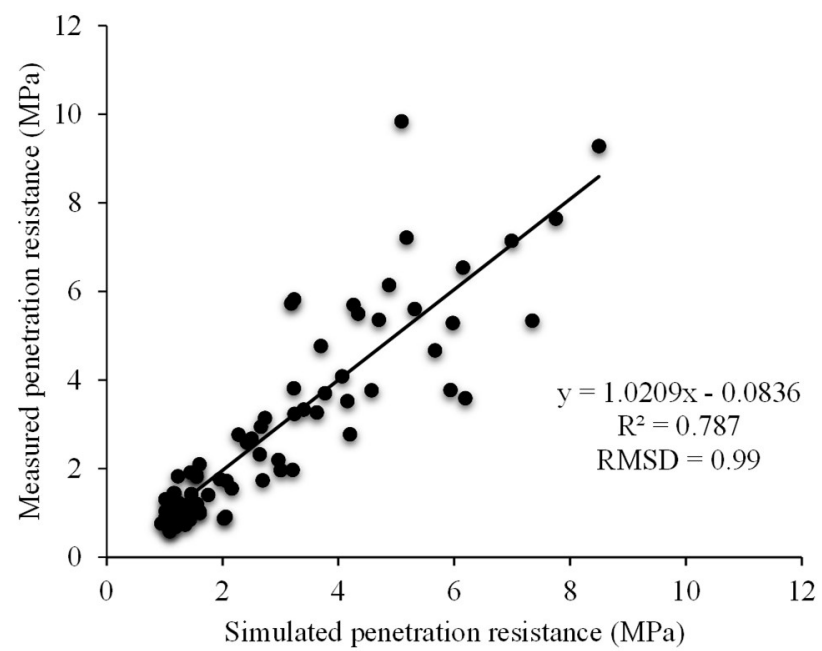

FIGURE 11. Comparison of measured and simulated penetration resistance (PR) values using the Mielke et al. (1994) model.

Correction of penetration resistance values as a function of soil moisture

The penetration resistance values corrected for soil moisture and evaluated using the Busscher method and the proposed method are presented in Figure 12. The figure illustrates the response of the correction methods to the five $\theta_{\text {ref }}$ values used. In the proposed method of correction, the data have lower variation with variation in soil moisture. The trend was maintained under all the $\theta_{\text {ref }}$ values evaluated. Conversely, the Busscher method exhibited greater variation, particularly for extreme $\theta_{\text {ref }}$ values $\left(0.10\right.$ and $\left.0.30 \mathrm{~kg} \mathrm{~kg}^{-1}\right)$. Both correction methods exhibited similar performance for the $0.20 \mathrm{~kg} \mathrm{~kg}^{-1} \theta_{\text {ref. }}$.

The RMSD values for the methods are listed in Table 3. The proposed method yielded more stable values under 
varying $\theta_{\text {ref }}$ values, with an average value of 0.29 . The lowest error in the Busscher method was observed under the $\theta_{\text {ref: }} 0.20$ $\mathrm{kg} \mathrm{kg}^{-1}$. In addition, Table 4 lists the $\mathrm{PR}_{\text {reference }}$ values for each adopted $\theta_{\text {ref, }}$ as well as the corrected penetration resistance values using both methods. Notably, under all moisture conditions, the proposed method yielded values closes to the actual value. Vaz et al. (2011) have previously reported that the Busscher et al. (1997) method is effective only under conditions where the reference and measured soil moisture values are close, and where the two moisture levels vary considerably, the Busscher et al. (1997) method could yield even negative values, which is inconsistent with reality. Such observations were also made in the present study based on an $\theta_{\text {ref }}$ of $0.30 \mathrm{~kg} \mathrm{~kg}^{-1}$ and soil moisture values close to $0.15 \mathrm{~kg} \mathrm{~kg}^{-1}$.

The correction method in the present study is simple and relies only on soil moisture values. However, similar to the case with the Busscher method, it is necessary to know in advance the relationship between penetration resistance and soil moisture. In addition, it is critical to note that the relationship varies based on the average soil bulk density, as demonstrated by Vaz et al. (2013). Therefore, the penetration resistance correction equation presented in Figure 2 is reliably under an average bulk density of $1.27 \mathrm{~g} \mathrm{~cm}^{-3}$. For other bulk density values, the appropriate correction equation is likely to be different.

The $\theta_{\text {ref }}$ values used to correct penetration resistance values enabled the evaluation of model performance over broad ranges. However, other moisture-linked values could be adopted as reference values. For example, Vaz et al. (2011) used only values corresponding to a soil tension of $10 \mathrm{kPa}$, which would be close to a moisture level of $0.27 \mathrm{~kg} \mathrm{~kg}^{-1}$ in the soil analyzed in this paper.

Vaz et al. (2011) adopted the Jakobsen \& Dexter (1987) model for penetration resistance value correction, and they performed corrections using reference soil bulk density and soil moisture data. That is, the corrected value did not rely on new penetration resistance measurements. Using such a method, the Jakobsen \& Dexter (1987) model, for data correction at soil moisture levels listed in Table 3 ( 0.10 to 0.30 $\mathrm{kg} \mathrm{kg}^{-1}$ ), the correction error was 0.501 (RMSD). The results highlight the advantage of using the measured penetration resistance value for the calculation of correction values based on moisture levels, as carried out in the method proposed in the present paper.

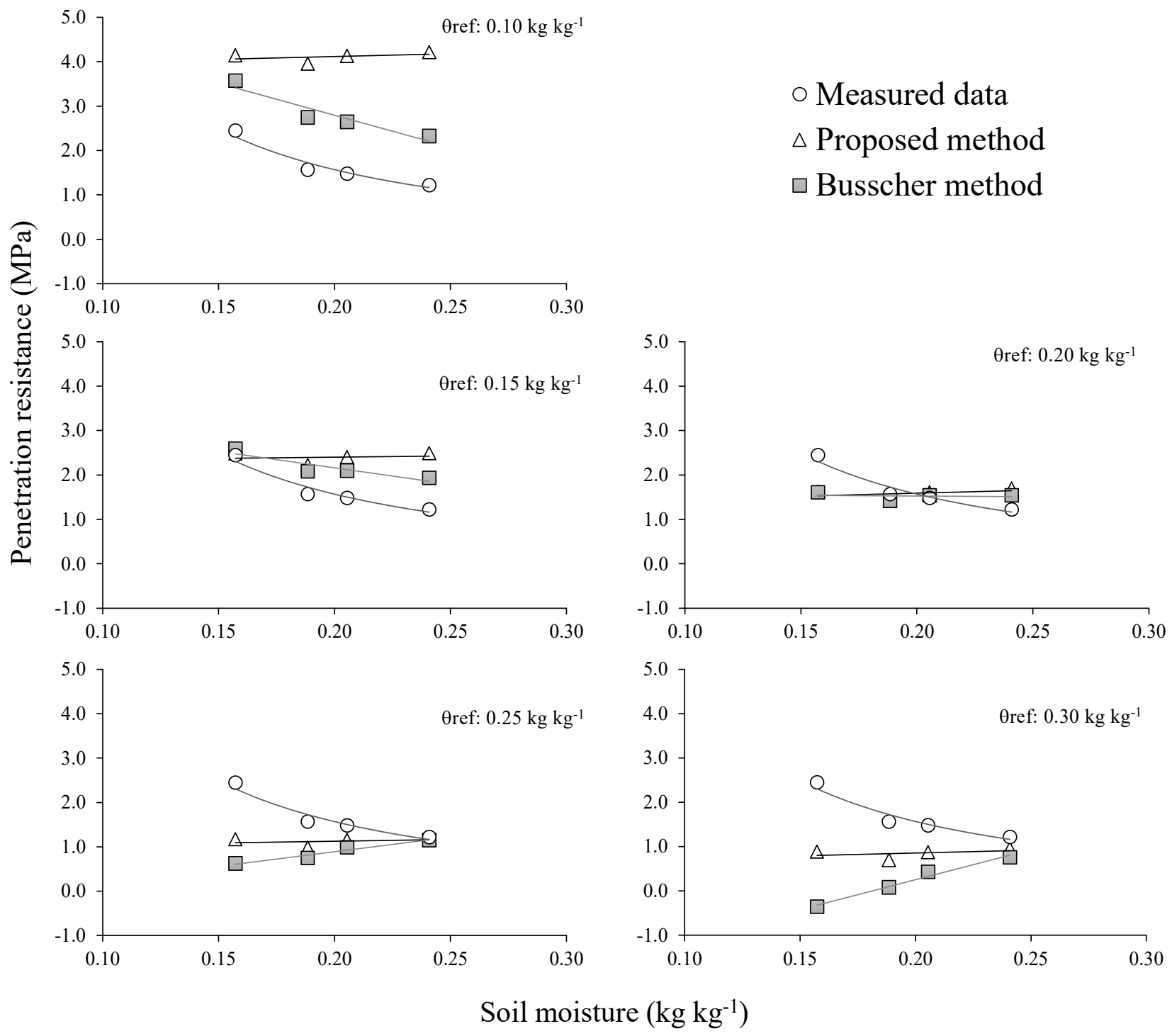

FIGURE 12. Correction of soil penetration resistance as a function of soil moisture $\left(\mathrm{kg} \mathrm{kg}^{-1}\right) . \theta_{\text {ref: }}$ soil moisture reference value used to evaluate the models. 
TABLE 3. Root mean square deviation (RMSD) of penetration resistance correction methods as a function of soil moisture.

\begin{tabular}{ccc}
\hline Reference soil water content $\left(\mathrm{kg} \mathrm{kg}^{-1}\right)$ & RMSD- proposed method & RMSD- Busscher method \\
\hline 0.10 & 0.29 & 1.63 \\
0.15 & 0.28 & 0.54 \\
0.20 & 0.29 & 0.35 \\
0.25 & 0.30 & 0.58 \\
0.30 & 0.29 & 0.99 \\
\hline
\end{tabular}

TABLE 4. Comparison of reference penetration resistance (PRreference) values and the corrected penetration resistance values based on the proposed method and the Busscher methods.

\begin{tabular}{cccc}
\hline Reference soil moisture content $\left(\mathrm{kg} \mathrm{kg}^{-1}\right)$ & PR $_{\text {reference }}(\mathrm{MPa})$ & Proposed method (MPa) & Busscher method (MPa) \\
\hline 0.10 & 4.39 & 4.11 & 2.83 \\
0.15 & 2.66 & 2.40 & 2.18 \\
0.20 & 1.87 & 1.59 & 1.53 \\
0.25 & 1.42 & 1.13 & 0.88 \\
0.30 & 1.13 & 0.85 & 0.23 \\
\hline
\end{tabular}

\section{CONCLUSIONS}

The soil resistance to penetration in a Red Latosol, measured using a bench-top electronic penetrometer (laboratory) is, on average, almost three-fold that measured using a static penetrometer (field conditions). In addition, a decrease in soil moisture enhances the difference. Comparison of values obtained by different types of penetrometers can only be done following adjustment of the data. Regarding the models tested for penetration resistance simulation, the Jakobsen \& Dexter model (1987) was superior in relation to the others (Busscher \& Sojka, 1987; Mielke et al., 1994; Busscher et al., 1997). However, in addition to soil moisture, this model also takes into account soil bulk density. When only soil moisture was taken into account, the Mielke et al. (1994) model was the optimal model. Here, we propose a novel method of correcting penetration resistance values obtained under different conditions. However, the method requires prior knowledge of the relationship between penetration resistance and soil moisture, and the relationship varies based on average soil bulk density. The method was tested with several reference moisture values and the errors presented were stable and lower than 0.30 (RMSD).

\section{ACKNOWLEDGMENTS}

The authors thank the Coordination for the Improvement of Higher Education Personnel (CAPES) for the partial funding of the project via the Pró-Equipamentos/2014 Program.

\section{REFERENCES}

Busscher WJ, Sojka RE (1987) Enhancement of subsoiling effect on soil strength by conservation tillage. Transactions of ASAE 30:888-892.

Busscher WJ, Bauer PJ, Camp CR, Sojka RE (1997) Correction of cone index for soil water content differences in a coastal plain soil. Soil and Tillage Research 43:205-217. DOI: https://doi.org/10.1016/S0167-1987(97)00015-9

Embrapa - Empresa Brasileira de Pesquisa Agropecuária (2018) Sistema brasileiro de classificação de solos. Embrapa, 356p.
Hernanz JL, Peixoto H, Cerisola C, Sánchezgirón V (2000) An empirical model to predict soil bulk density profiles in field conditions using penetration resistance, moisture content and soil depth. Journal of Terramechanics 37:167-184. DOI: https://doi.org/10.1016/S0022-4898(99)00020-8

Jakobsen BF, Dexter AR (1987) Effect of soil structure on wheat root growth, water uptake and grain yield. A computer simulation model. Soil and Tillage Research 10:331-345. DOI: https://doi.org/10.1016/0167-1987(87)90022-5

Junior DDV, Bianchini A, Valadão FCA, Rosa RP (2014) Penetration Resistance according to penetration rate, cone base size and different soil conditions. Bragantia 73:171-177. DOI: http://dx.doi.org/10.1590/brag.2014.013

Medvedev VV (2009) Soil penetration resistance and penetrographs in studies of tillage technologies. Eurasian Soil Science 42:299-309. DOI: https://doi.org/10.1134/S1064229309030077

Mielke LN, Powers WL, Badri S, Jones AJ (1994) Estimating soil water content from soil strength. Soil and Tillage Research 31:199-209. DOI: https://doi.org/10.1016/0167-1987(94)90080-9

Filho EAM, Silva AP, Figueiredo GC, Gimenes FHS, Vitti AC (2014) Compared performance of penetrometers and effect of soil water content on penetration resistance measurements. Revista Brasileira de Ciência do Solo 38:744-754. DOI: http://dx.doi.org/10.1590/S0100-06832014000300006

Silva WM, Bianchini A, Cunha CA (2016) Modeling and correction of soil penetration resistance for variations in soil moisture and soil bulk density. Engenharia Agrícola 3:449459. DOI: http://dx.doi.org/10.1590/1809-4430-

Eng.Agric.v36n3p449-459/2016

Vaz CMP, Manieri JM, De Maria IC, Tuller M (2011) Modeling and correction of soil penetration resistance for varying soil water content. Geoderma 166:92-101. DOI: https://doi.org/10.1016/j.geoderma.2011.07.016

Vaz CMP, Maria IC, Genuchen MTV (2013) Scaling the dependency of soil penetration resistance on water content and bulk density of different soils. Soil Science Society of America Journal 77:1488-1495. DOI: https://doi:10.2136/sssaj2013.01.001 